\title{
User difficulties in e-learning system
}

\begin{abstract}
An interface is very effective to encourage the users intention and engage them to achieve their destination in e-learning process. This research aims to explore the user needs through learner experience on using e-learning interface. The case study is needed to identify and to collect the learner problem in e-learning, especially in User Interface. It took three months to get the user interface problems, such as login page, choice menus, and table of contents, content presentation, interactive media, and presentation of exercises, example solutions, and self-assessment. The research took three months data collection of forty-seven students in Mulawarman University. Based on this research, it shows that the communicativeness of the interface is the most difficult part, followed by choices menu, and self-assessment. Meanwhile, the example solutions and login page are among the least difficult of the menu.
\end{abstract}

Keyword: E-learning; User difficulties; User interface; User requirement 